\title{
Surgical treatment with dental implants in a patient with secondary loss of teeth and osteoporosis caused by an imbalance of vitamin $D$
}

\author{
Ekaterina Diachkova @ ( ) Elizaveta V Abramova, Natalia A Blagushina, \\ Svetlana Tarasenko
}

Dental Surgery, I M Sechenov First Moscow State Medical University, Moscow, Russian Federation

\section{Correspondence to} Dr Ekaterina Diachkova; secu2003@mail.ru

Accepted 22 September 2020

Check for updates

(C) BMJ Publishing Group Limited 2020. No commercial re-use. See rights and permissions. Published by BMJ.

To cite: Diachkova $\mathrm{E}$, Abramova EV, Blagushina NA, et al. BMJ Case Rep

2020:13:e235585

doi:10.1136/bcr-2020-

235585

\section{SUMMARY}

In recent years, the success of long-term dental implants has remained problematic, especially because of the increasing rate of mineral balance changes in patients with partial loss of teeth, regardless of their age, race and sex. This article describes the experience of 6 years of treatment with dental implants in a patient with secondary loss of tooth and mineral imbalance (osteopenia) due to vitamin D deficiency, in collaboration with endocrinologist. Along with basic dental care, special medicine was prescribed for this pathology. The bone system was monitored through regular blood tests, skeletal bone densitometry and X-ray of the maxillofacial region. This management plan allowed dental implants to be maintained in good condition for 7 years.

\section{BACKGROUND}

The problem of dental row restoration has remained relevant for many years. Dental implants have been used actively for the past 30-40 years for dental rehabilitation of patients with partial secondary absence of teeth. The most popular criteria for success at the implant level are mobility, pain, radiolucency and loss of peri-implant tissues $(>1.5 \mathrm{~mm})$, as well as the absence or presence of peri-implantitis, suppuration and bleeding. The main success factors at the prosthetic level were technical complications/prosthetics, adequate function and aesthetics for 5 years. Patient satisfaction criteria included discomfort and paraesthesia absence, satisfaction with appearance and ability to experience/taste. Success in implant dentistry should ideally measure the long-term primary outcomes of the implant prosthetic complex. ${ }^{1}$

However, due to the technogenic impact and world environmental situation, this type of treatment is becoming less effective, leading to the increasing risk of dental implant failure, mainly because of associated metabolic disturbances such as osteopenia and osteoporosis. ${ }^{2-4}$ The number of people who were not previously at risk of osteoporosis, such as menopausal women with decreased oestrogen levels, is increasing, and the association with age and gender is becoming less obvious.

Currently there are no contraindications for dental implants in patients with osteoporosis. However, the implant stabilisation process may be different for patients with this pathology. A longer implant stabilisation period is noted compared with healthy patients. A more thorough study of bisphosphonate use is required since there is currently insufficient information. There is also evidence of patients with osteoporosis taking bisphosphonates. Intravenous administration of these drugs increases the risk of developing osteonecrosis compared with oral administration. The presence of osteoporosis does interfere with the mechanical stability of dental implants, although this does not adversely affect their osseointegration. ${ }^{5-8}$ It can be assumed that, if the primary mechanical stability in patients with osteoporosis is longer, then it is worth revising the terms of orthopaedic treatment and the load on the implant. Here, we will focus on osteoporosis caused by an imbalance of vitamin D. There are studies that prove a direct link. ${ }^{9}$ Adequate intake of vitamin D and calcium is considered an important component in treating osteoporosis. ${ }^{10}$ The deficit is especially pronounced in women older than 50 years, which is also confirmed by studies. ${ }^{11}$ It can be concluded that the imbalance of vitamin D indirectly affects the implant engraftment. In the Russian Federation and other countries, more and more scientists are paying attention to the need for an integrated approach for treating patients with secondary partial absence of teeth and metabolic disturbances, by adding endocrinologists to the medical team and working closely with them.

An analysis of the current situation in Russia and the scientific literature revealed the need for further randomised and multicentre studies to develop a comprehensive algorithm for examining and treating patients in this category.

\section{CASE PRESENTATION}

A 51-year-old woman presented at a private dental clinic in 2013 with complaints of recurrent pain in the left temporomandibular joint (TMJ), difficulty chewing solid food and a prolonged absence of teeth in the lower jaw.

On examination, the facial configuration was unchanged, the opening of the mouth was not limited. There was an S-shaped deviation of the lower jaw, with an amplitude of more than $2.5 \mathrm{~cm}$, and a click in the region of the left TMJ, in which hypermobility and slight pain were noted during palpation.

From the side of the oral cavity, the patient lacked teeth at positions 3.6, 3.7 and 4.6. The mucous membrane was pale pink and moderately moist. Palpation was painless. The width of the alveolar 


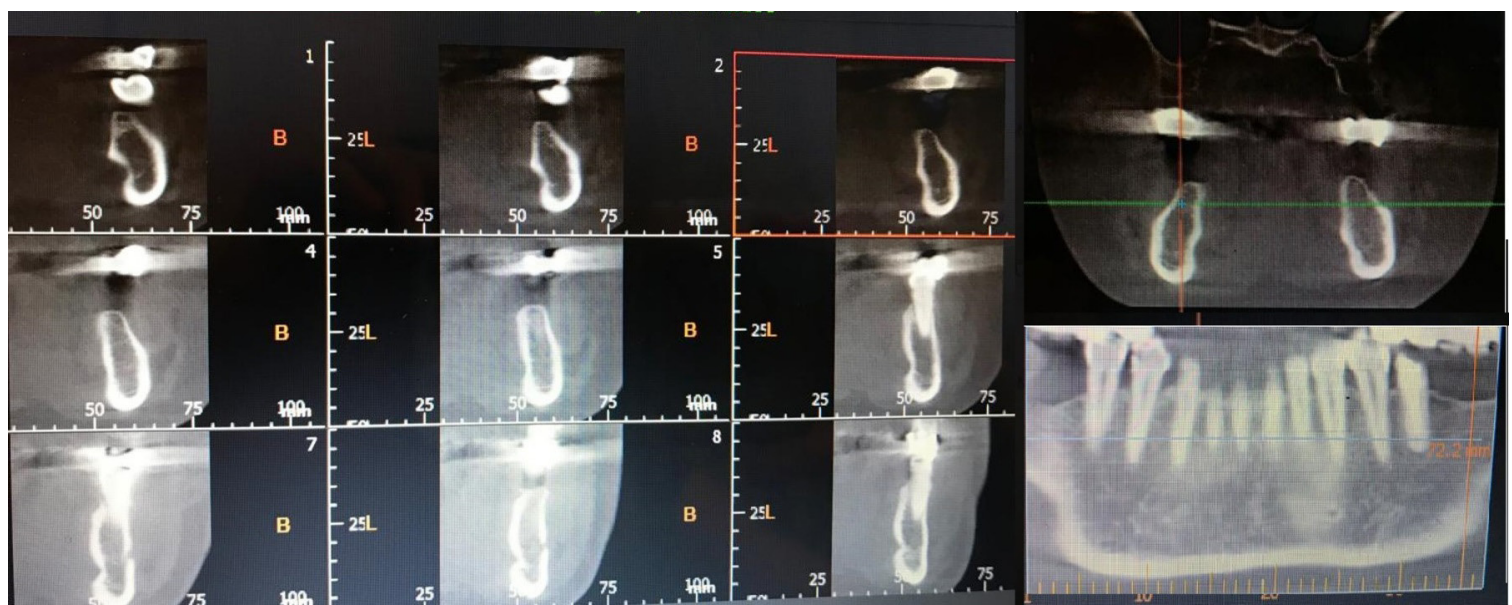

Figure 1 Cone beam CT of the patient before dental implantation.

ridge when measured with a surgical caliper was $8 \mathrm{~mm}$ (area 3.6), $8.2 \mathrm{~mm}$ (area 3.7) and $7.8 \mathrm{~mm}$ (area 4.6).

An initial intraoral photo of 3.6, 3.7 and 4.6 tooth was taken. According to available clinical data, a preliminary diagnosis was made by a parallel method. A provisional diagnosis of TMJ dysfunction was made. To clarify the diagnosis, we proposed performing an MRI and condylography, but the patient refused.

When conducting cone beam CT, the mandible parameters were as follows: the height and width of the alveolar ridge (to the canal of the lower alveolar nerve) for 4.6 tooth was $6 \times 12 \mathrm{~mm}$, for 3.6 tooth was $6.5 \times 14 \mathrm{~mm}$ and for 3.7 tooth was $6.8 \times 13.5 \mathrm{~mm}$ (figure 1 ).

At the preoperative stage, haematology, biochemistry, haemoglobin A1c, coagulogram, parathyroid hormone (PTH), antibodies to thyroid peroxidase, triiodothyronine and thyroid stimulating hormone lab tests were performed.

According to the results, the patient's indicators were within the reference values for haematology and biochemistry. However, the coagulation system result indicated the PTH level was above normal (7.36 compared with normal values for a given age and gender, which do not go beyond $6.9 \mathrm{pg} / \mathrm{L}$ ).

She had a history of long-term use of oral contraceptives and had not reached menopause at the time of dental implant installation.

To verify the diagnosis and further examination, the patient was referred to a gynaecologist-endocrinologist. As an additional assessment, a skeleton densitometry was performed, which revealed decreased bone density in the lumbar vertebrae to 0.831 and the left femoral head to 0.71 . The patient was diagnosed with osteopenia. Then, a sequential treatment was carried out. After investigation, the endocrinologist prescribed $70 \mathrm{mg}$ of alendronic acid orally once a week, along with daily calcium 500 mg two times per day and Alpha D3-Teva at $1 \mu \mathrm{g}$.

After the targeted treatment began, a series of dental measurements were performed. Therapeutic and surgical sanitation of the oral cavity was complete.

Alfa Bio DFI implants (Alpha-Bio Tec, Israel) with dimensions of $3.75 \times 10 \mathrm{~mm}$ (position of missing 4.6 tooth), $3.75 \times 11.5 \mathrm{~mm}$ (position of missing 3.6 and 3.7 teeth) were installed.

Antibacterial (Augmentin $625 \mathrm{mg}$ three times per a day for 7 days), anti-inflammatory and analgesic therapy (nimesulide for pain) were prescribed, along with antiseptic baths of the oral cavity (water solution of chlorhexidine $0.05 \%$ ).

The postoperative period was unremarkable. During the first postoperative follow-up, the gingiva in the surgical field were slightly swollen, without pathological changes. According to the patient, there was no pain. Sutures were removed on the seventh day, and the patient was given individual hygiene recommendations. Control examinations were carried out 3 months later.

Healing abutments were installed 3 months after dental implantation over two visits because of economic considerations (figure 2). Two and fourweeks later (total terms of gum formation), the orthopaedic stage was provided (figures 3 and 4), and the implant crowns were fixed (transocclusion fixation for 4.6,; cement fixation 3.6 and 3.7).

The patient was followed by an endocrinologist and a dental surgeon for 6 years. She underwent professional hygiene examination at a dental office every 6 months.

Every recall was followed by a follow-up examination of the operative field: the level of the crestal bone was assessed, as well as a visual assessment of the keratinised gingiva, in a patient survey.

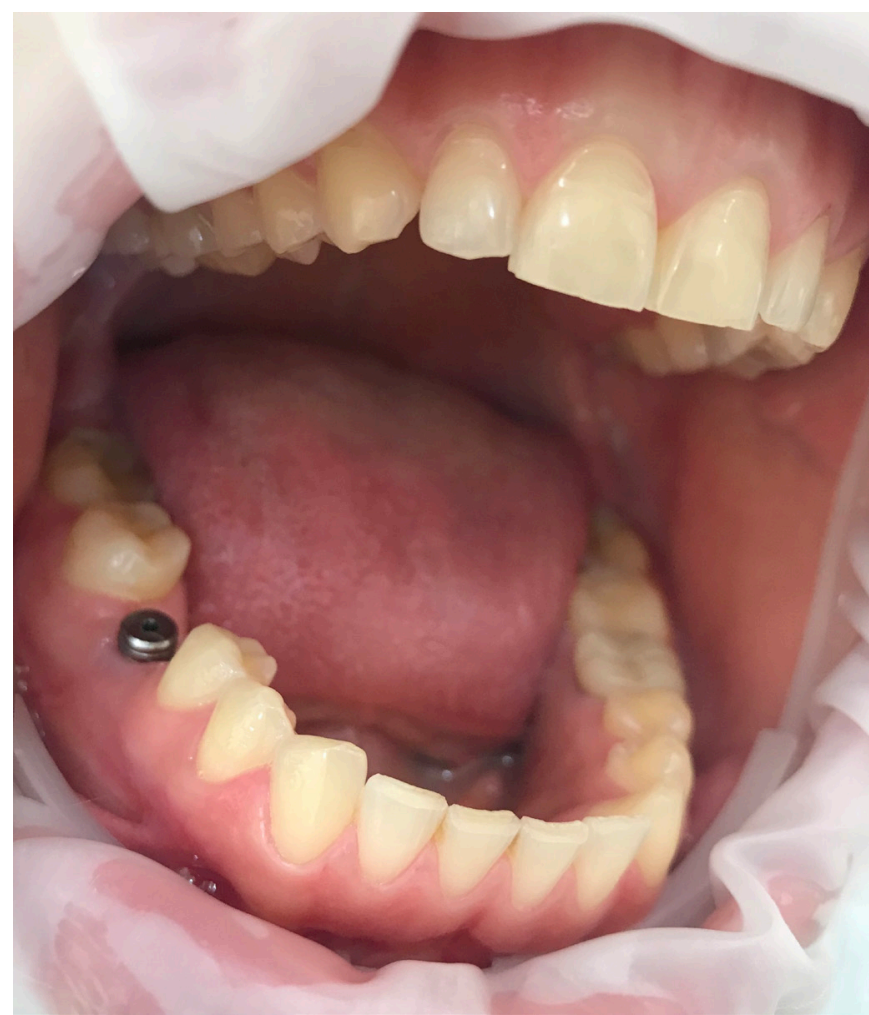

Figure 2 Inserted healing abutment in position 4.6 of dental implant. 


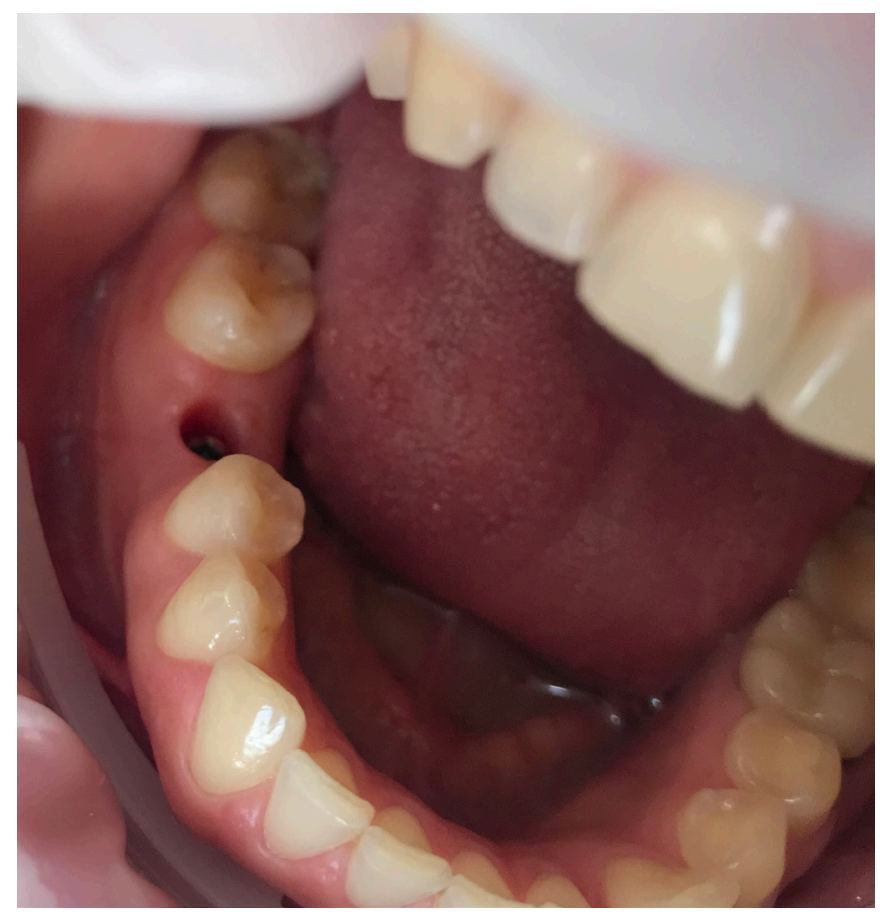

Figure 3 Condition of tissue in position 4.6 of dental implant after healing abutment removal in 2 weeks.

During the visual oral examination, the gingiva were pale pink and moderately moist; the width of the attached gingiva was $4.5 \mathrm{~mm}$, the depth during probing was $1-1.5 \mathrm{~mm}$, no

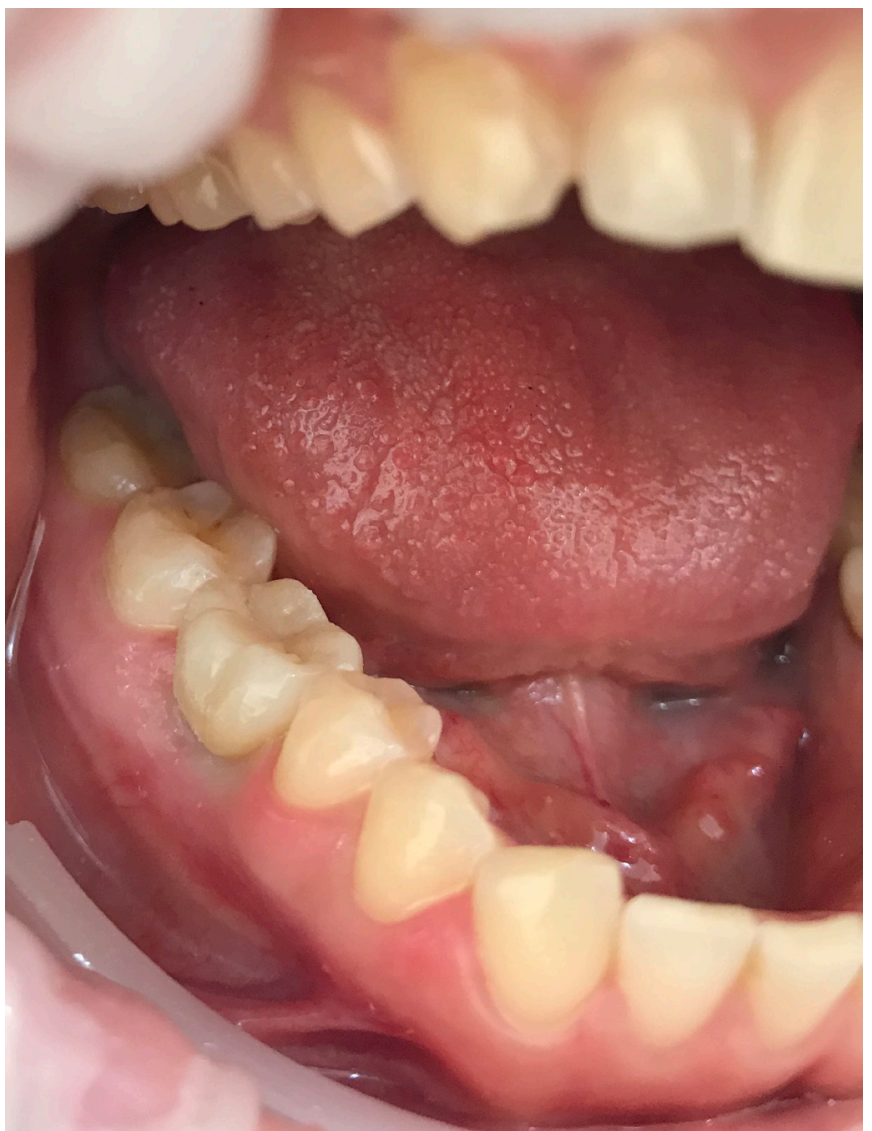

Figure 4 View of the oral cavity after prosthetic stage.

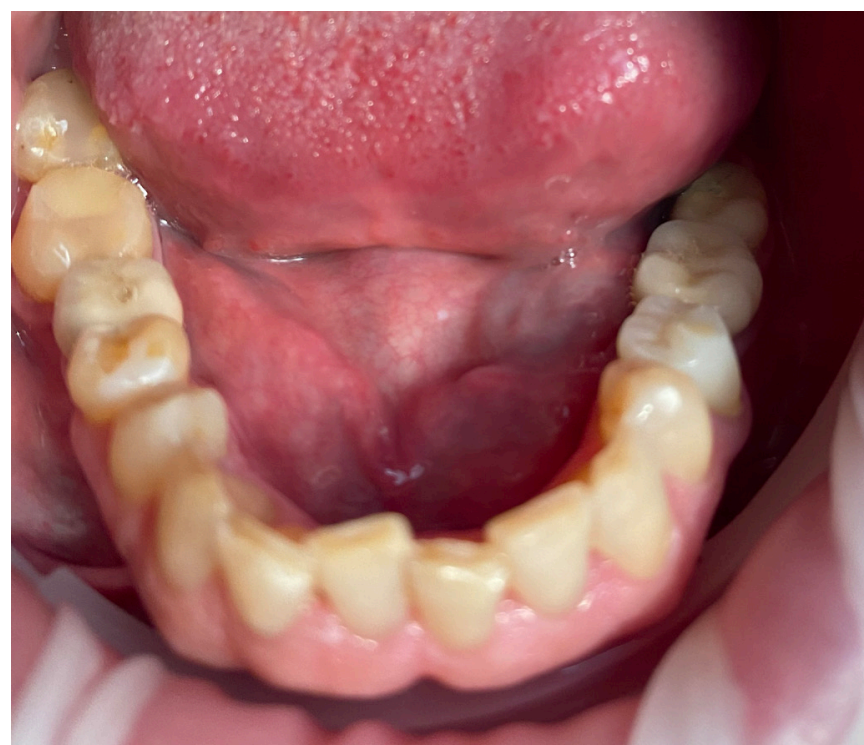

Figure 5 The view of oral cavity 6 years after prosthetic stage.

bleeding or suppuration, and there was no bone loss according radiological examination.

Six years after dental implantation, the loss of crown cementation in dental implants was noted at tooth positions 3.6 and 3.7. The treatment of the gingival bed and the implant shaft, and X-ray of this area with subsequent fixation of the crowns was carried out. The condition of soft tissue was excellent, and oral hygiene was satisfactory (figure 5), the displacement of dental rows was also diagnosed.

According to the results of the X-ray examination, after 6 years, the dental implants were well-positioned, with no critical resorption of the bone tissue surrounding them (figure 6).

The patient continued therapeutic dental treatment due to new foci of odontogenic infection.

About 6 months ago, the patient underwent densitometry and control hormonal tests, the results of which revealed a vitamin D deficiency (20 at a rate of $30-100 \mathrm{ng} / \mathrm{mL}$ ), an increased PTH level (up to 10.13 at a rate of $6.9 \mathrm{pg} / \mathrm{L}$ ) and maintained foci of osteopenia at the control points of the skeleton: in the lumbar region, T-criterion was $-1.0 \mathrm{SD}, \mathrm{Z}$-criterion was $+0.2 \mathrm{SD}$; in the neck of the femur on the left, T-criterion was $-1.0 \mathrm{SD}$, Z-criterion was +0.2 SD (figure 7 ). The patient's therapy was changed for 2 months after the endocrinologist prescribed 7000 IU of oral cholecalciferol drops (14 drops every day for 8 weeks, then 1000 IU continuously).

After 2 months, the vitamin D and PTH returned to normal range, and maintenance therapy with vitamin D3 was prescribed (1000 conventional units once per day). Further examination was recommended to exclude metabolic syndrome (due to the presence of hypertension and increased body weight-in 6 years, the patient's body mass index (BMI) had increased from 25 to 29.2).

The patient gave oral and written consent for the clinical examination, investigation, treatment and use of materials.

\section{GLOBAL HEALTH PROBLEM LIST}

- In recent years, the percentage of patients with mineral imbalances, such as vitamin D deficiency (not only in women aged more than 50 years and patients with endocrine disease), affecting the bones and teeth has been increasing. 


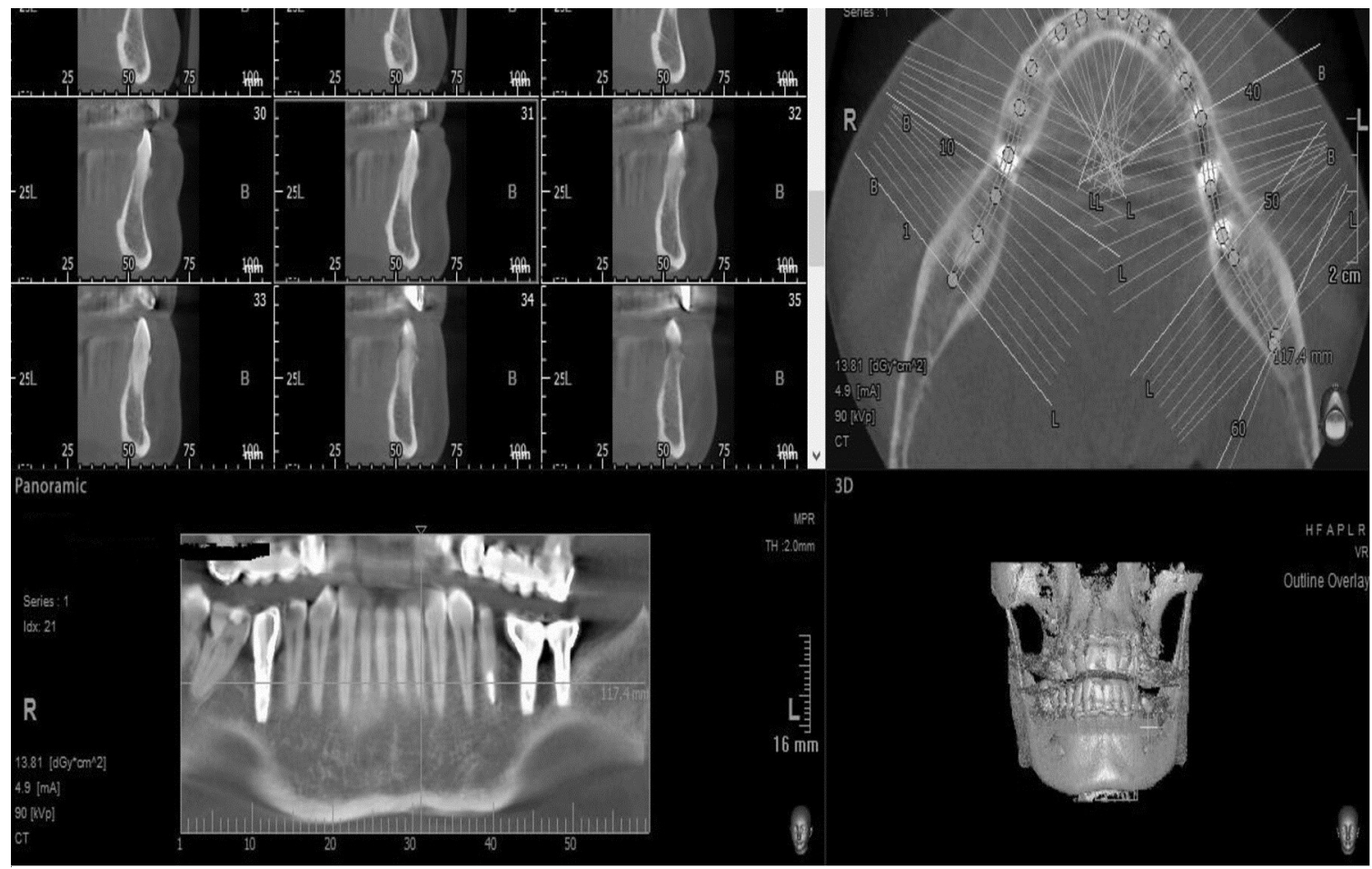

Figure 6 Cone beam CT of the patient 6 years after dental implantation. The position of the dental implants is satisfactory, without bone resorption around them.

- There is a problem of dental implant integration in patients with mineral imbalance.

- There is a requirement for a management protocol for patients with mineral balance disturbances, including examinations and the endocrinologist's prescriptions.

\section{GLOBAL HEALTH PROBLEM ANALYSIS}

Currently, the number of people with mineral balance disturbances is increasing. This condition, including osteoporosis, causes an imbalance in remodelling and bone resorption, and can lead to increased risk of bone fractures. Today a connection has been established, not only with somatic diseases but with changing lifestyles of people around the world. ${ }^{9}$

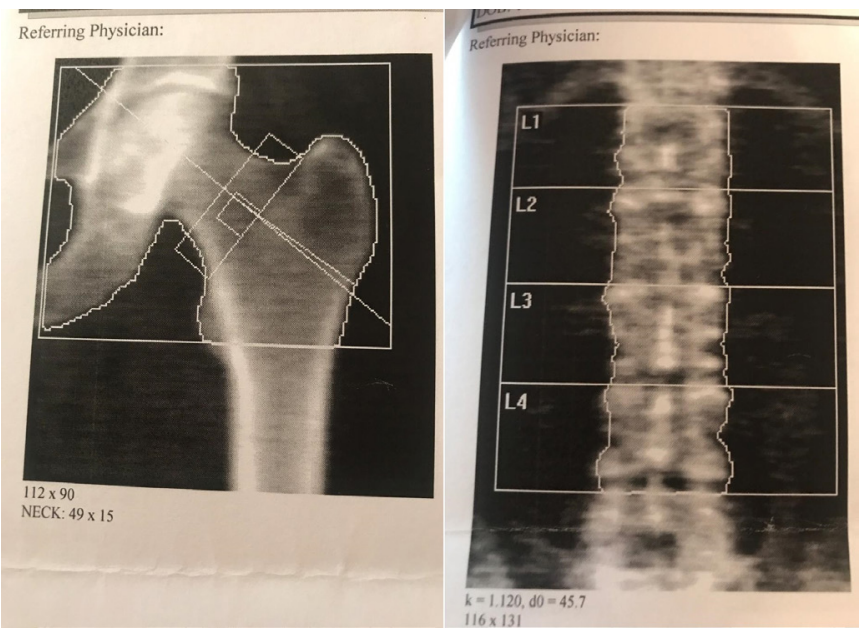

Figure 7 Densitometry results 6 years after dental implantation. The endocrinologist had considered the decrease of bone density level in the main reference points and changed antiresorptive therapy on vitamin D.
According to the WHO statistics, osteoporosis has become an important public health problem worldwide. One in three women and one in five men over the age of 50 years will have an osteoporotic fracture in their lifetime. ${ }^{10}$

According to You et al, today, the risk for osteoporosis is significantly associated with age, vitamin D intake, metabolic equivalent of task scores, weight, neck and hip circumference, waistline in the population. Also, the role of fat distribution, erectile dysfunction, menopause and alcohol abuse in osteoporosis should be given more consideration in clinical practice. ${ }^{11}$ There is an increasing number of patients with a history of osteoporosis. This forces us to seek the best treatment options in oral surgery.

Currently, more and more factors affect long-term dental implantation, resulting in patients with partial secondary absence of teeth, including various disorders affecting bone mineral metabolism that were previously associated with an increase, for one reason or another, of the thyroid hormone, and found in postmenopausal women. In the last 5 years, endocrinologists have correlated vitamin D deficiency and PTH concentration, and therefore, the status of mineral metabolism. ${ }^{12-14}$ Moreover, we want to note that, in recent years, this relationship has been less and less characteristic of the risk group for osteoporosis (white women older than 50 years with established menopause), and has become more and more characteristic of young and middleaged patients, which may be associated with lifestyle (prolonged stay in enclosed spaces, low insolation, diet and nature and so on). Against the background of such changes, the risk of an unfavourable outcome of surgical treatment of patients with partial secondary absence of teeth naturally increases when dental implants are installed. ${ }^{4-8}$ Therefore, a close cooperation between the dental surgeon and endocrinologist is now required, since timely antiresorptive therapy can increase the 5 -year survival of implants to $100 \%$, regardless of the patient's age and gender. 
Thus, considering the growth of hormonal imbalance in patients with partial secondary absence of teeth, the collaboration with endocrinologists to correct the existing metabolic disorders to increase the survival time of dental implants and surgical treatment, in general, remains relevant.

Recent scientific works are aimed at assessing bone tissue changes during dental operations. For example, some patients take constant hormone replacement therapy, or have hyperparathyroidism, thyrotoxicosis and hyperprolactinemia. The surplus of glucocorticoid hormone induces osteoporosis, and patients have poor primary stability of the implants due to osteogenesis inhibition

Oki et al investigated the effects of continual intermittent influence of PTH on dental implant stability in the presence of osteoporosis, using rabbit models and creating artificial osteoporosis with the use of PTH in different forms before and after implantation. ${ }^{15}$ The authors measured the implant stability coefficient immediately and after 2 and 4 weeks. According to a histological study, the quality and quantity of bone around dental implants were better in the groups of animals with adequate compensating therapy for osteoporosis.

Recent studies show the success of additional substances for covering dental implant surfaces, like lithium chloride application, increases osseointegration. Tests have shown that the properties of this material can improve its primary component. Lithium chloride stimulates osteogenesis and differentiation of osteoblasts. ${ }^{16}$ Thus, this material can be used to treat patients with osteoporosis.

Dentists do not have clear guidelines on managing patients with disturbance of mineral balance. This may impair the treatment with dental implants, as these patients take bisphosphonates on an ongoing basis. For example, one article reveals a problem, dentists hesitate to help people with osteoporosis. In this group of patients, the risk of developing osteonecrosis increases; dental manipulations can provoke its development if there is no clear sequence of actions. ${ }^{17}$ Several known risk factors are associated with the development of antiresorptive-related osteonecrosis of the jaw, including invasive dental procedures, such as tooth extraction, dental implant or apical/periodontal surgery. ${ }^{18}$ This study recommends focusing on the prevention of odontogenic infection to reduce the number of invasive open bone manipulations. However, even when all attempts to avoid surgery have been made, the chance of its need remains. The resumption of antiresorptive therapy is recommended 2 months after implantation. Discontinuation of medicines is recommended for 2 months with the consultation of an endocrinologist.

Summarising all data presented in the article, the method of temporararily stopping bisphosphonates before implantation is widespread to achieve bone healing, but there are no clear recommendations for oral surgeons in case of other diseases or conditions connected with the disturbance of mineral balance. That is why the risk of complications after dental implantation increases in these patients. Dentists should be aware of the manifestations of osteoporosis, and know how to assess the laboratory test results and risk factors that cause complications during manipulation and how to treat them in collaboration with an endocrinologist.

Schwarz et al analysed the studies and considered osteoporosis, osteopenia, thyroid disease, hepatitis, BMI as well as radiation and chemotherapy as potential risk factors for implant loss, but observed no association with peri-implantitis. They decided that it could be questioned whether existing studies evaluating risk factors/indicators for periimplantitis were adequately powered to detect associations with rare disorders, and that evidence suggesting systemic conditions (other than diabetes) to be a risk factor/indicator for peri-implantitis was limited. ${ }^{19}$

\section{Learning points}

- Patients with a partial secondary loss of teeth must be recommended to get blood test performed for key signs of mineral imbalance and other diseases before dental implantation (this analysis should be performed only for patients at risk: women over 50 years, and patients with endocrine pathology, mineral imbalance and osteoporosis).

- If bone mineral metabolism disorder is detected, patient should consult an endocrinologist for further investigations and, if necessary, special therapy with vitamin $D$ for the indication.

- Timely and adequate therapy prescribed by endocrinologist increases the 5 -year success rate of dental implants to $100 \%$, regardless of the patient's age and gender.

Contributors ED: conceptualisation and design, surgery and monitoring. NAB: monitoring, analysis and interpretation of data. EVA: review problem in the global health, analysis and writing part of article. ST: drafting the article or revising it critically for important intellectual content and final approval of the version published.

Funding Supported be Russian Science Excellence Project 5-100.

Competing interests None declared.

Patient consent for publication Obtained.

Provenance and peer review Not commissioned; externally peer-reviewed.

ORCID iD

Ekaterina Diachkova http://orcid.org/0000-0003-4388-8911

\section{REFERENCES}

1 Papaspyridakos $\mathrm{P}$, Chen $\mathrm{C}-\mathrm{J}$, Singh $\mathrm{M}$, et al. Success criteria in implant dentistry: a systematic review. J Dent Res 2012;91:242-8.

2 Janushevich 00, Kozlova MV, Mkrtumjan AM, et al. Kachestvennaja ocenka cheljustnyh kostej u pacientov pri kompleksnoj antiosteoporeticheskoj terapii. Rossijskaja stomatologija 2014;7:34-40.

3 Mashchenko EA, Khesin RA, Malichenko SB, et al. Efficacy of the comprehensive antiresorptive therapy at different stages of surgical rehabilitation in dentition defects in female patients with postmenopausal osteoporosis. Med Soc Ex 2016;19:71-9.

4 Gunko MV. Osteoporosis and dental implantation. Stomatologiia 2009;6:73-8.

5 Merheb J, Temmerman A, Rasmusson L, et al. Influence of skeletal and local bone density on dental implant stability in patients with osteoporosis. Clin Implant Dent Relat Res 2016;18:253-60.

6 de Medeiros FCFL, Kudo GAH, Leme BG, et al. Dental implants in patients with osteoporosis: a systematic review with meta-analysis. Int J Oral Maxillofac Surg 2018:47:480-91.

7 Tsolaki IN, Madianos PN, Vrotsos JA. Outcomes of dental implants in osteoporotic patients. A literature review. J Prosthodont 2009;18:309-23.

8 Alghamdi HS. Dental implant placement in focal osteoporotic bone marrow defect: a case report. Int J Case Rep Imag 2017;8:817-21.

9 Lips P, van Schoor NM. The effect of vitamin D on bone and osteoporosis. Best Pract Res Clin Endocrinol Metab 2011;25:585-91.

10 Holick MF, Siris ES, Binkley N, et al. Prevalence of vitamin D inadequacy among postmenopausal North American women receiving osteoporosis therapy. J Clin Endocrinol Metab 2005;90:3215-24.

11 You L, Li F, Feng W, et al. Osteoporosis risk-assessment related lifestyle and metabolic factors: a population-based study. Clin Invest 2019;9:33-46. https://www. openaccessjournals.com/articles/osteoporosis-riskassessment-related-lifestyle-andmetabolic-factors-a-populationbased-study.pdf

12 Svedbom A, Hernlund $E$, Ivergård $M$, et al. Osteoporosis in the European Union: a compendium of country-specific reports. Arch Osteoporos 2013;8:137.

13 Hernlund $\mathrm{E}$, Svedbom A, Ivergård $\mathrm{M}$, et al. Osteoporosis in the European Union: medical management, epidemiology and economic burden. Arch Osteoporos 2013;8:136.

14 Lips $P$, Hosking D, Lippuner $K$, et al. The prevalence of vitamin D inadequacy amongst women with osteoporosis: an international epidemiological investigation. J Intern Med 2006;260:245-54 


\section{Global health}

15 Oki Y, Doi K, Makihara Y, et al. Effects of continual intermittent administration of parathyroid hormone on implant stability in the presence of osteoporosis: an in vivo study using resonance frequency analysis in a rabbit model. J App/ Oral Sci 2017:25:498-505.

16 Choukroun J, Khoury G, Khoury F, et al. Two neglected biologic risk factors in bone grafting and implantology: high low-density lipoprotein cholesterol and low serum vitamin D. J Oral Implantol 2014;40:110-4.
17 Waskiewicz K, Oth 0 , Kochan N, et al. Des facteurs de risque généralement négligés enchirurgie orale et en implantologie: le taux élevé de LDL-cholestérol et le taux insuffisant de la vitamin D. Revue médicale de Bruxelles 2018;39:70-7.

18 Fretwurst T, Grunert S, Woelber JP, et al. Vitamin D deficiency in early implant failure: two case reports. Int J Implant Dent 2016;2:24.

19 Schwarz F, Derks J, Monje A, et al. Peri-Implantitis. J Clin Periodontol 2018;45(Suppl 20):S246-66.

Copyright 2020 BMJ Publishing Group. All rights reserved. For permission to reuse any of this content visit

https://www.bmj.com/company/products-services/rights-and-licensing/permissions/

BMJ Case Report Fellows may re-use this article for personal use and teaching without any further permission.

Become a Fellow of BMJ Case Reports today and you can:

- Submit as many cases as you like

- Enjoy fast sympathetic peer review and rapid publication of accepted articles

Access all the published articles

Re-use any of the published material for personal use and teaching without further permission

\section{Customer Service}

If you have any further queries about your subscription, please contact our customer services team on +44 (0) 2071111105 or via email at support@bmj.com.

Visit casereports.bmj.com for more articles like this and to become a Fellow 